Pedagogía y Saberes No. 49

Universidad Pedagógica Nacional

Facultad de Educación. 2018, pp. 213-223

\title{
Una singularidad desencarnada: el problema de la enseñanza en la era digital $^{*}$
}

\section{Artículo de investigación}

A disembodied singularity : the problem of teaching in the digital age

Uma singularidade desencarnada: o problema do ensino na era digital

Para citar este artículo:

Rengifo, J. (2018). Una singularidad desencarnada: el problema de la enseñanza en la era digital. Pedagogía y Saberes, $49,213-223$

* Este artículo es un avance del proyecto de investigación titulado "El canto como práctica pedagógica en las comunidades afrodescendientes del Pacífico colombiano", gracias al apoyo de la Universidad Santiago de Cali, y con la participación de la Asociación Eslabón Cultural, la Fundación Investigación Creativos con la comunidad de cantaoras del grupo Integración Pacífico de la comuna trece de la ciudad de Cali. En este se hace una problematización de la práctica pedagógica de los educadores contemporáneos.

** Profesor Universidad Santiago de Cali. Magister en filosofía e investigador del grupo GISOHA. Correo electrónico: jalexrecar@yahoo.es Código ORCID: http://orcid.org/0000-0001-7527-1241 


\title{
Resumen
}

Este artículo es un ejercicio de reflexión que indaga, de un modo crítico, por la práctica académica del educador, sus esfuerzos por enseñar en la era digital y la imposibilidad de tal empresa. Aquí se expone la caducidad del maestro en cuanto significante gráfico carente de significado contextual, poseedor de un discurso que hoy aparece, ante la singularidad narrativa del escolar, como esencialmente trivial, porque no le dice nada valioso. Ello tiene una explicación muy sencilla: la vida de la singularidad escolar emerge ante un mundo digital como dinámica, fluida, móvil e interactiva, lo que aniquila de raíz la palabra superflua del educador e instituye un proceso de aprendizaje continuo: la ligereza de los contenidos digitales a través de los dispositivos móviles e interactivos. No obstante, al final del artículo se muestra una posible salida a esta cuestión, de la mano de un concepto que sirve para alimentar la esperanza, un proceso de formación al que se denomina "reconstrucción de la praxis formativa en una espiral de fuga".

\section{Palabras clave}

enseñar; aprender; discurso; singularidad narrativa; espacio digital interactivo

\begin{abstract}
This article is an exercise of reflection that investigates, in a critical way, the academic practice of the educator, his efforts to teach in the digital era and the impossibility of such purpose. Here is exposed the expiration of the teacher as a graphic significant lacking contextual meaning, holder of a discourse that today appears, before the narrative singularity of the scholar, as essentially trivial, because it does not say anything valuable. This has a very simple explanation: the life of the school singularity emerges before a digital world as dynamic, fluid, mobile and interactive, which annihilates at the root the superfluous word of the educator and institutes a continuous learning process: the lightness of the contents digital through mobile and interactive devices. However, at the end of the article a possible solution to this question is shown, from the hand of a concept that serves to nourish hope, a training process called "reconstruction of the formative praxis in a spiral of flight.
\end{abstract}

\section{Keywords}

teaching; learning; discourse; singularity narrative; interactive digital space

\section{Resumo}

0 artigo é um exercício de reflexão crítica sobre a prática acadêmica do educador, os seus esforços por ensinar na era digital e a impossibilidade de um tal empreendimento. Aqui se apresenta a caducidade do professor enquanto significante gráfico carente de significado contextual, possuidor de um discurso que aparece hoje, diante a singularidade narrativa do escolar, como essencialmente trivial, pois não diz nada de valor. Tudo isso tem uma simples explicação: a vida da singularidade escolar emerge diante um mundo digital como dinâmica, fluida, móvel e interativa, questão que aniquila de raiz a palavra supérflua do educador e institui um processo de aprendizagem contínuo: a leviandade dos conteúdos digitais através dos dispositivos móveis e interativos. Aliás, no fim do artigo, mostra-se uma possível saída para esta questão utilizando um conceito que serve para alimentar a esperança, um processo de formação denominado "reconstrução da práxis formativa numa espiral de fuga".

\section{Palavras-chave}

ensinar; aprender; discurso; singularidade narrativa; espaço digital interativo 


\section{Introducción}

Cuando Zaratustra tenía treinta años abandonó su patria y el lago de su patria y marchó a las montañas. Allí gozó de su espíritu y de su soledad y durante diez años no se cansó de hacerlo. Pero al fin su corazón se transformó, y una mañana, levantándose con la aurora, se colocó delante del sol y le habló así: “¡Tú gran astro! ¡Qué sería de tu felicidad si no tuvieras a aquellos a quienes iluminas! Durante diez años has venido subiendo hasta mi caverna: sin mí, mi águila y mi serpiente te habrías hartado de tu luz y de este camino. Pero nosotros te aguardábamos cada mañana, te liberábamos de tu sobreabundancia y te bendecíamos por ello. ¡Mira! Estoy hastiado de mi sabiduría como la abeja que ha recogido demasiada miel, tengo necesidad de manos que se extiendan. Me gustaría regalar y repartir hasta que los sabios entre los hombres hayan vuelto a regocijarse con su locura, y los pobres, con su riqueza. Para ello tengo que bajar a la profundidad: como haces tú al atardecer, cuando traspones el mar llevando luz incluso al submundo, jastro inmensamente rico! Yo, lo mismo que tú, tengo que hundirme en mi ocaso, como dicen los hombres a quienes quiero bajar. ¡Bendíceme, pues, ojo tranquilo, capaz de mirar sin envidia incluso una felicidad demasiado grande! ¡Bendice la copa que quiere desbordarse para que de ella fluya el agua de oro llevando a todas partes el resplandor de tus delicias! ¡Mira! Esta copa quiere vaciarse de nuevo, y Zaratustra quiere volver a hacerse hombre. (Nietzsche, 1997, p. 19).

En el mundo contemporáneo Zaratustra, nuevamente, se ha sumergido en sus pensamientos, le ha quedado lo único que puede hacer: subir a la montaña a gozar de su soledad. La soledad es la única condición de posibilidad del existir de los diferentes, el maestro. Se ha de acallar aquello que produce comezón: su hombre superior, su labor pedagógica, su alumbramiento cual partera, su mármol por esculpir ha desaparecido: el educando. Produce comezón aquello que genera incomodidad, pesadez, ensimismamiento, retiro, una pequeña pausa, un alto en el camino, un momento de sosiego, un abrir los ojos para preferir la piedra en ellos, pensar. Desde luego, se implora por el hombre de la manada: el youtuber, el reguetonero, el futbolista, el comerciante. Del hombre superior se han de aborrecer su protesta, su denuncia, su palabra, su enseñanza. A su águila le han roto las alas. Su serpiente ha sido vituperada. Sus tres transformaciones las ha cercenado el Cervero ${ }^{1}$ de la información: la

1 Perro de tres cabezas de la mitología griega que habitaba el inframundo para cuidar la puerta de ingreso a este, y devorar a los mortales que intentaran pasar por ella. red, el chat, los no-espacios móviles ${ }^{2}$. Su luz ha sido absorbida por algo que hoy se ha descubierto: un terrible, pero real, agujero negro. Un agujero que todo lo engulle, lo desvanece, pero del cual nada retorna, nada emerge, nada fluye, toda luz se ha de apagar: la superficialidad de un encuentro sin actores, el acto educativo contemporáneo vaciado sobre una mente de consumo, la del educando, una singularidad desencarnada de todo proceso de formación real.

¿Qué es enseñar hoy, en el contexto de la era digital? ¿Es posible una enseñanza transformadora? ¿Qué papel les corresponde a las singularidades educador y educando? ¿De qué modo el proceso de enseñanza ha cedido lugar ante el surgimiento de los paquetes de aprendizajes interactivos, ciberespaciales, virtuales? Estas cuestiones ofrecen una aproximación al derrotero que sigue este escrito. Enuncian a modo de problemas una tesis fundamental que será desarrollada como introducción.

Hoy enseñar es un problema, por cuanto ha desaparecido. Ha desaparecido en la medida en que hoy solo hay un proceso de aprendizaje. Hoy la enseñanza ha sido sustituida por la apropiación autónoma de contenidos digitales. Lentamente ha ido desapareciendo como proceso formativo ${ }^{3}$, para dar lugar a unos procesos instruccionales de aprehensión de contenidos interactivos, virtuales y mediáticos ${ }^{4}$. La educación como proceso de enseñanza ha muerto. La razón: el mundo teórico del educador no puede competir con el de las imágenes superfluas del dispositivo móvil que se transmiten por WhatsApp o You Tube. Su verdugo, aquel con quien establecía, históricamente, su relación: el educando ${ }^{5}$; un mundo en ebullición con

2 En este artículo se realiza una reflexión sobre los dispositivos móviles como no-espacios pedagógicos que niegan la singularidad educador. Quien la niega es el educando, la singularidad desencarnada. ¿Cómo la niega? A través del uso indiscriminado de esta (la singularidad) en el aula de clases, el chat se superpone como otro mundo a la alteridad maestro.

3 Llamo formar al proceso por medio del cual la relación educadoreducando transcurría en torno a la construcción colectiva integral de ambos. El primero en calidad de mediador, el segundo en calidad de indagador.

4 Entiéndase que se está hablando solo de la relación que establece de forma autómata la singularidad educando con su dispositivo móvil. Que quede claro, que este ejercicio de caligrafía no es una crítica a los procesos de educación virtuales, sino a uno sumamente peligroso: el uso cultural que se le está dando al celular.

5 Llamo singularidad desencarnada al educando, al joven de hoy, debido a que siendo un ser único, cuyo modo de vida es dinámico, fluido, interactivo -y por ello, disperso-, se da a la tarea de alejarse, retirarse de su naturaleza creadora y la sustituye por una relación simbiótica con el dispositivo móvil. A través de dicha relación este se desencarna de su ser autentico; más aún, desencarna a la alteridad educador, 
quien entablaba un lazo afectivo de apego, de odio, de amor, de desamor, las más enconadas batallas. Es el mismo educando quien ha hecho perecer el sentido de la acción de enseñar, en la medida en que esta aparece siempre trivial: ¿qué educador puede competir hoy contra You Tube?, por ejemplo. El discurso del educador es trivial en la medida en que es unidireccional, monotemático y simple y llanamente oral. El de YouTube, por el contrario, es plural, multitemático, interactivo, dinámico y no necesariamente oral. Esto sin mencionar el uso indiscriminado de las redes que permiten que emerja un multiuniverso: el del mundo de la singularidad desencarnada, en un espacio y momento concreto. Acción que ni un titán del libre pensamiento puede hacer emerger.

El aprendizaje está garantizado por la superfluidad, ligereza, utilidad automatizada de los dispositivos móviles, los contenidos interactivos y las redes sociales. Lo que se aprende no es un saber. Es ante todo un no-saber. Un no-saber es un poseer: estar lleno de información "útil". Un no-saber es liviandad: navegar, consumir y aparentar, red, modas y selfis. Hoy se aprende sin necesidad de ir a la escuela. Claro está, se aprende lo que la sociedad actual produce, miseria (Rengifo, 2015): la narcoestética de las telenovelas que hacen del mafioso un héroe social, los reality shows que hacen del prójimo un infierno; las noticias que convierten el sufrimiento en rating; el género musical del reguetón que hace del modo de vida del maleante un ícono social, de la mujer un objeto de consumo sin espíritu, y del dinero la cúspide del éxito. El consumo desmedido de información es un imperativo cultural social. Se ha creado entonces una terrible ficción: cuanta más información mediática se consuma día a día, momento a momento, segundo a segundo, más conocimiento se posee. Desde luego este es un muy mal chiste. Pero es el panorama social en el que estamos inmersos. No se entiende que el conocimiento nada tiene que ver con la información. El conocimiento tiene todo que ver con el desarrollo de un organismo en unos procesos teóricos y prácticos de formación sostenibles en el espacio y en el tiempo: conocer es un proceso. El concepto de información, por el contrario, es una categoría que nace a partir de la mitad del siglo Xx, desde el ámbito del discurso tecnológico contemporáneo. En este, la información se instituye en el paradigma del conocimiento actual. ¿Por qué? Porque evita la tarea de pensar; evita la tarea de buscar ser; evita la tarea de problematizar, el cómo, el porqué, el para qué, no pueden surgir. Una sociedad informada no es una sociedad de

en la medida en que hace del espacio educativo un universo de discursos audiovisuales por medio del chat, lo que irremediablemente niega a la persona maestro. conocimiento. Una sociedad informada es solo una sociedad de demagogos.

Enseñar en este contexto, es, por ello, una odisea, una utopía, un desafío, un sueño romántico. No se puede enseñar en la era digital. Enseñar no es instruir. Por ello no se puede enseñar. Enseñar es formar. Esta máxima ya ha caducado, por lo que hoy no se enseña, se aprende a ser socialmente laboral, esto es: competente. Entiéndase cómo los enunciados competente e información comparten un mismo origen discursivo, y una misma periodicidad histórica: el siglo $\mathrm{xx}$, por lo que hablamos de una misma episteme (Foucault, 1968). Enseñar era privilegio del maestro: agente activo investido de poder institucional y prestigio social.

En el centro del proceso de enseñanza es necesario colocar al maestro y su saber para reconocer todos los elementos que componen este proceso, de por sí complejo, y para devolver a la enseñanza el estatuto de práctica de saber entre prácticas. [...] Los conocimientos, cuyo modo de existencia cultural pasa por la práctica de la enseñanza, encuentran en el maestro su primer depositario. (Zuluaga, 1996, p. 14).

Hoy el educador es borrado de un solo tajo del sistema perceptual de la singularidad-narrativa escolar $^{6}$ haciendo clic. El dispositivo móvil del segundo niega la singularidad del primero, su discursividad. El autismo tecnológico pone en situación de afásico al educando. El mundo se reduce a una autosugestión placeba de contenidos informativos e interactivos. La realidad educador deviene trivial ante el fenómeno digital. El primero es el mejor representante de lo sólido en la era de lo líquido (Bauman, 2004).

En este esfuerzo de mostrar el problema de enseñar en la era digital, el método que más nos sirve para entender este fenómeno social contemporáneo es el deconstructivo: proceso de denuncia de lo que se puede ver, de lo que ofrece la sociedad en su acción educativa y cultural, a través de la cual se hace evidente el alejamiento práctico que hay entre enseñar y aprender; la primera práctica obedece al maestro, la segunda al educando. La primera práctica ha muerto, la segunda le ha matado. Aprender hoy no es un proceso. Es un mecanicismo instruccional inercial. Por eso la necesidad de paquetes interactivos digitales informativos y, ante todo, veloces. La velocidad hoy es una necesidad existencial. La lentitud de un proceso largo, pausado, minucioso, se hace obsoleta. Por eso

6 Por singularidad narrativa escolar entiendo la emergencia difusa, emotiva y hedonista del joven contemporáneo, quien incapaz de cualquier proceso discursivo formal apela a una fraseología desprovista de cualquier contenido epistemológico, y lo sustituye por contenidos informáticos ligeros. 
la enseñanza ha muerto. En cambio, el aprendizaje de la —cada vez más rápida - información es menester.

Este estudio se nutre del análisis conceptual de autores cómo Sigmund Bauman en su texto $L a$ modernidad líquida (2004), de quien tomamos el concepto de fluidez, en este caso el del dispositivo móvil que permite un multiuniverso de significaciones discursivas, frente al mundo sólido y aburrido del educador; Nietzsche, en sus intempestivas tres y cuatro: Schopenhauer cómo educador (2000a) y Sobre el porvenir de nuestras instituciones educativas (2000b) y en su Zaratustra (1997), quien nos ayuda para entender el fenómeno de la educación como un acontecer, ante todo, cultural; María Cristina Corea e Ignacio Lewkowicz, quienes en su texto Pedagogía del aburrido (1995) nos han mostrado el uso superfluo que hoy el educando hace de internet, y la situación de aburrimiento que este vive en la escuela; Pedagogía crítica, resistencia cultural y la producción del deseo (1991), de Peter McLaren, nos sirve para evidenciar la crisis del sistema escolar americano basado en su modelo educativo conservador. De igual modo, esta reflexión, hecha en un tono de melancolía, desasosiego y protesta, ha sido reforzada por el análisis situacional del entorno académico que pudimos evidenciar, en estos diez años de trabajo pedagógico formativo, en cursos universitarios tales como: Semiología I y II en la Fundación Universitaria Autónoma de Occidente en el año 2006; Filosofía y Educación dictado en la universidad del Valle durante dos semestres en el 2008; Semiología, dictado en la Universidad Pontificia Bolivariana de Palmira en el mismo año; Seminario de Filosofía I y II, Antropología Filosófica, Historia Comparativa de las Religiones, Antropología y Sociología de las Religiones, dictado en la Fundación Universitaria Católica Lumen Gentium durante cuatro semestres (2010-2012). Las conferencias sobre ética y pedagogía, ética y religión, realizadas en el Instituto Julián Mendoza Guerrero de Buga, entre otros; y, en este último periodo (2015-2016) se ha nutrido fuertemente del trabajo emprendido en la Universidad Santiago de Cali en el curso Epistemes y Saberes. Por último, recoge la experiencia académica vivida en distintos colegios de Cali, dictando siempre Filosofía en grados diez y once, respectivamente, desde el año 2000. En consecuencia, el margen de acción, la población, el periodo histórico y la muestra son muy concretas: una ciudad pluriétnica, multicultural, diversa, circunscrita a un Estado social de derecho, metida de cabo a rabo en las lógicas de consumo de un mundo global, propio del siglo XXI, donde los adolescentes cambiaron el cigarrillo por la marihuana, la música por el reguetón, los juegos por los celulares y la familia por el grupo.
Este discurrir reflexivo transcurrirá de la siguiente manera. En un primer momento, se mostrará el concepto de enseñanza en un mundo globalizado, de los no-espacios, los dispositivos móviles, con el ánimo de problematizar su acontecer hoy. En un segundo momento, mostrar cómo es que hoy, estos no-espacios - los dispositivos móviles- instituyen procesos de aprendizaje triviales, pero, al fin y al cabo, aprendizajes, ante el advenimiento de la singularidad escolar, que ha sido caracterizada como desencarna$d a$. Por último, se concluirá con una posible salida a esta cuestión, a través de lo que en otros trabajos hemos llamado praxis formativa.

\section{Significante sin significado}

Con todo, me es igual de imposible callar o no callar esta desgracia. Porque habiendo proporcionado una dádiva a los mortales estoy uncido al yugo de la necesidad, desdichado. En el tallo de una caña me llevé la casa, el manantial del fuego robado que es para los mortales maestro de todas la artes y gran recurso. De este mal pago ahora la pena, clavado con cadenas bajo el éter. (Esquilo, 2000, p. 5).

Enseñar en la era digital es realmente una labor titánica. Habrá que ser un Prometeo para anunciarles a los mortales lo que no desean oír. Habrá que ser un Prometeo para devolver el fuego a los hombres. Sin embargo, del mismo modo que Zararustra, como ya se dijo, habrá de quedar envuelto en la soledad de sus pensamientos. Aquel, Prometeo, será clavado de nuevo a una roca para que sus entrañas sean comidas eternamente. Un alumbramiento hoy ha de ser más que un bello nacimiento, el padecimiento de un aborto biológico (Bolk, 2007) crónico, inacabado, mal hecho, no formado, deficiente; y la negligencia de un acontecer social (Nietzsche, 2000a): una nada substancial perdida en el idiotismo de la red (Rengifo, 2016). Echar las perlas a los cerdos, y darles las cosas sagradas a los perros es lo que los educadores hacen todos los días. La enseñanza como proceso, y el maestro como guía han sido acallados por el influjo comercial de los no-espacios móviles. Desde luego, tal situación puede ser comprensible. La enseñanza como proceso duele. El maestro como guía incomoda. El aprendizaje, en cambio, es placentero, no cuesta, es inmediato, es fluido, evita pensar, no incomoda. Las redes, YouTube, por el contrario, son agentes de significación contextual inmediata: informan, mantienen al zombi conectado, informado, generan lógicas de placer.

¿Qué puede enseñar un maestro convertido en docente hoy? En el mundo actual, ¿de qué, realmente, 
podría hablarle, susurrarle al oído un educador a una singularidad educable? ¿Cómo podría un educador transmutar en sujeto vivo que enuncia palabra de incomodidad, de confrontación, de transgresión? La realidad vital, orgánica educador ¿de qué modo podría, en cuanto significante gráfico corporal, que tematiza, personifica e instituye un ya instituido sin institución que lo reivindique, aunque desinstituido por destituyentes, no agotar su significado en el ocaso de un día escolar? ¿Por qué la singularidad educable ha de desencarnar, comercialmente, esto es, reducir a la singularidad educador a su función académica, negando la existencia de este? ¿La facultad del existir es propiedad, hoy, del maestro? Si existe el ser maestro, ¿cómo es que la pluralidad narrativa del sujeto educable es capaz de borrarla de su sistema perceptual de un solo trazo, haciendo clic?

\begin{abstract}
Un poco después llegaron Polemarco y Adimanto, hermano de Glaucon, Nicerates, hijo de Nicias, y algunos otros que volvían de la Pompa. Polemarco, al alcanzarnos, me dijo: -Sócrates, me parece que os retiráis de la ciudad. -No te equivocas, le respondí. - ¿Has reparado cuántos somos nosotros?-Sí . -Pues ó sois más fuertes que nosotros, ó permaneceréis aquí. -Hay otro medio, que es convenceros de que tenéis que dejarnos marchar. -¿Cómo podremos convencernos, si no queremos escucharos? -En efecto, dijo Glaucon, entonces no es posible. -Pues bien, replicó Polemarco, estad seguros de que no os escucharemos. - ¿No sabéis, dijo Adimanto, que esta tarde, la carrera de las antorchas encendidas en honor de la diosa se hará á caballo? - ¿Á caballo? es cosa nueva. ¿Correrán á caballo, teniendo en la mano las antorchas, que en la carrera habrán de entregar los unos á los otros? -Sí, dijo Polemarco, y además habrá una velada que merece la pena de verse. Iremos allá después de cenar, y pasaremos el rato alegremente con muchos jóvenes, que allí encontraremos. Quedaos, pues, y no os hagáis más de rogar. -Ya veo que es preciso quedarse, dijo Glaucon. -Puesto que lo quieres así, le respondí, nos quedaremos. (Platón, 1979, pp. 63-64).
\end{abstract}

En los pocos flujos de relación que ciertas singularidades auténticas han entablado de manera creativa, honesta, genuina, con su otredad: el poeta con el poema, y el poema con el poeta; el músico con la composición y esta con él; el cantante con su canto y este en su emanar; el actor con su personaje y este en él; el investigador con lo que lo hace ser investigador, su relación fluida con un algo (...) ${ }^{7}$; el campesino con la tierra y ella con él; en todas ellas la relación está

7 Utilizo los tres puntos entre corchetes para sugerir un pensamiento que queda insinuado, que le permite al lector llenarlo. fundada en el entretejer. En un devenir orgánico en el que lo uno y lo otro se hacen uno solo en un fluir específico. ¿Y el maestro de hoy, ¿puede establecer algún flujo de relación con lo otro que habría de complementarlo? Desafortunadamente, no. Hoy el flujo de la singularidad educada en devenir maestro solo puede relacionarse consigo mismo. Lo que lo completaba ha desaparecido. Lo que le daba sentido a un flujo de relación mediante la acción reflexiva del diálogo crítico lo ha remplazado por un flujo de relación distinto. Otro pedagogo y otro discurso han usurpado su territorio. Otro devenir no orgánico ha desterritorializado su entorno situacional específico, y este está siendo incapaz de reterritorializarlo (Deleuze, Guatari, 1997). Lo que antaño era su espacio de poder hoy no lo es. Lo que de antaño era su discurso de poder ya no lo es. Lo que de antaño representaba su figura: significante gráfico corporal cargado de un semántica proposicional viva, significaba un algo, figuraba algo, signo poder, ha dejado de existir. Aunque este se resista a perecer, su situación es terminal. Enfermos terminales son todos aquellos que siguen intentando ser lo que ya el otro pedagogo les arrebató: al sujeto orgánico de su relación.

Si no hay relación educativa es porque se ha dejado de enseñar. Hoy no se puede enseñar porque no hay con quién conversar, hablar, reír, compartir, llorar, crear. Por lo tanto en la sociedad global, ciberespacial contemporánea, solo se da un acto académico: el aprendizaje. Pero, iy no se ha dicho que el maestro ya no puede enseñar porque su flujo relacional le ha sido amputado? Desde luego. Por eso hoy las singularidades educables solo aprenden del otro pedagogo, con el otro pedagogo, no del sujeto vivo maestro. El nuevo flujo de relación educativa es muy evidente: aprehensión de paquetes de información (Rengifo, Pinillo y Díaz, 2016). Para ello no se necesita un maestro. Un dispositivo móvil e interactivo es todo lo que requiere el educando de hoy. Este flujo de relación se ha solidificado, paradójicamente en la era de la fluidez (Bauman, 2004).

Al maestro le corresponde un único papel: dramatizar la información (Corea y Lewkowicz, 1995) que la singularidad narrativa educable compró, pagó, al ingresar al sistema educativo. El educando paga por recibir unos paquetes informativos, paquetes escolares (Chervel, 1991) pero alienando al sujeto vivo maestro. Lo reemplaza en su acción real, por otros paquetes informativos: el chat, el WhatsApp, la red. De tal modo que la singularidad educador deviene siempre trivial. Aunque su papel de cómico sea el mejor. El discurso largo, soso y desgastado del maestro está impedido de ser, de emerger, de generar algo, en las mentes dispersas de los educandos, 
pues el otro pedagogo se ha impuesto de un doble modo: primero, porque ha sustituido la palabra por la imagen. Segundo, porque se ha tornado placentero por cuanto no es este quien busca a aquel, es decir, no busca la relación, sino que por el contrario es fin, medio y mediador de la relación con la singularidad que se desencarna en él y con él. Este pedagogo no necesita dramatizar, pues su acción es la elección del educando siempre constante.

Ahora, si la educación es una comedia, lo es sin un comediante. Deviene un público en teatro que está viendo, no las escenas del espectáculo, sino leyendo entre sus propios pensamientos las dramaturgias pueriles de otros, y la propia, en el biespacio simultáneo del cuerpo sometido al entorno físico, y el cerebro (el imaginario) al espacio virtual: multiuniverso discursivo en imágenes que niegan lo otro, el maestro. Es un teatro sin comediante, pero que anhela por lo menos serlo por un rato, ganar la atención; y con un público que está sin reír, sin llorar, sin estar estando, aunque muy inquieto por lo que lleva el susurro del viento. Es este susurro del viento lo que mueve las lógicas del aula de clases mientras la palabra del educador lentamente empieza a desdibujarse.

\section{La enseñanza superflua}

¿Qué es enseñar hoy, en la era digital? Es, antes que nada, un mecanismo de legitimación de un discurso oficial, de carácter global: episteme tecnológica, que se expresa en enunciados como información, competencias, procesos de calidad, acreditación institucional, generación de nuevo conocimiento, entre otros. De no ser así, es un discurso sin peso. Tal discurso se vende como paquete de información en calidad de verdad. Principio de verdad que regula los lineamientos comportamentales de quienes acuden al espacio escolar. No obstante, comportamientos que no se instituyen en modo de direccionamiento del mismo; sino, más bien, como comportamiento laboralmente necesario por las lógicas de un sistema. Sistema que no propone una tipología de lo que el ciudadano debe ser: cada quien es como desee serlo. De hecho, toda la estructura del sistema está hecha para que cada quien haga lo que desee de sí, supuestamente. De ahí, el sentido de la educación actual, a nivel formal e informal: preparar en paquetes de información. Paquetes de información que se dan para cada tipo de personalidad específica. Tal destipologización obedece a una estrategia: el sistema solo desea mano de obra. Dos modos del ser emanan en este sentido: el público y el privado. En el mundo de vida público el sistema solo desea $-\mathrm{y}$ ha preparado todas sus instituciones para ello- mano de obra en un doble sentido, calificada y no calificada (Rengifo, 2016). La primera para el mundo global, la segunda para las migajas de la nación. En el mundo de la vida privada el sistema crea la ficción de dejar que cada quien haga lo que desee de su vida: credo, raza, ideología, comportamiento, lo que desee. Solo que lo que desee ser está amarrado a una educación cultural simple: ¡consuma lo que usted desea ser, en donde yo, la gran Hidra (Rengifo, 2016) le permito consumir! Todo el sistema está hecho para que se consuma en la vida privada y pública, creando la ilusión de que en su vida privada usted puede ser libre. La educación actual es esto: una compra y venta de paquetes informativos, para aquellas singularidades educables que se creen autónomas: aunque todos se preparan para ser mano de obra, cada vez más barata. De ahí la necesidad de que el educador diga palabra de verdad: la del sistema. La de los grandes sistemas de pensamiento (Foucault, 1979). La de las grandes historias oficiales. Lo que hace una mano de obra cada vez mejor calificada y con ello, realmente, más barata. Mas, en este esfuerzo de decir palabra de verdad, de enunciar enunciaciones lingüísticas legítimas, de proscribir acciones comportamentales deseables (Lipovetski, 1986), es para la singularidad narrativa educable, palabrería obsoleta, un susurro al viento, un comediante en un monólogo colectivo. Es un puro ejercicio demagógico de intentar decir lo que alguien no desea escuchar.

Enseñar hoy es un puro ejercicio ilocutivo que anhela tener fuerza perlocucionaria (Habermas, 1999), pero, en el instituyente de tal teatralidad, el educador, en su singularidad, la teoría es el contenido por enseñar: ejercicio de la razón pura. Pura, pura, y pura, especulación. Lo que lee el educando de aquel es el uso de la palabra obsoleta, ante su realidad dinámica y ciberespacial. Pero la acción formadora del maestro de otras épocas, quien educaba con sus actos, sus gestos, sus pausas, sus miradas, sus dichos, sus paradichos (Nietzsche, 2000b), es tan solo la anécdota de un pasado remoto. El educando no ve en este ni un modelo, ni un amigo, ni un personaje heroico: para eso están los jugadores de fútbol. Para eso están los cantantes famosos. Para eso está el líder de la tribu. Para eso está el youtuber. Cualquiera tiene hoy más autoridad y mejor prestigio que un educador.

Dejemos el romanticismo a un lado. Hoy se enseña el consumo de información en calidad de acción formadora para la vida. ¿Por qué? Por una realidad social muy simple, bastante simple: las universidades no necesitan maestros al modo antiguo, esto es, que formen; necesitan, requieren, de instructores del conocimiento informativo; es decir, de docentes que instruyan la nueva mano de obra mundial: el nuevo 
ejército de obreros transnacionales. En este sentido, la singularidad educador, en calidad de docente, vende su saber, hace marketing publicitario de su contenido epistémico teórico, y lo ofrece a sus clientes, educandos, como acción "formadora". Su puerilidad: sostener que su discurso teórico, ejercido desde la razón pura especulativa, es principio de verdad, es decir, es el conocimiento. Cuando lo que en realidad es, es un simple discurso en medio de un universo de discursos.

\section{El aprendizaje en la era digital}

La educación del siglo XxI, de la era digital, se ha caracterizado por la violencia con que los educandos perciben, enfrentan, viven y confrontan el espacio escolar. Los saberes barriales, vecinales y tribales son todos y cada uno de ellos llevados, trasladados a ese recinto, sin ningún tipo de filtro o control por las directivas de la institución. La razón: el imperio de los derechos del niño y del adolescente. El amparo jurídico-político: la Constitución Política de 1991 en su artículo (67), y la Ley General de Educación emanada en el año 1994 (Ley 115). Simbiosis jurídicosocial entre la jurisprudencia y la psicología. Se hizo del derecho de los niños un acto de psicologización sobre su proceso de enseñanza, que fue claramente determinado ya no en términos de enseñanza, sino de la dualidad conceptual enseñanza-aprendizaje, para regular el espacio, el tiempo, el currículo y los métodos que habrán de ser incluidos en las instituciones escolares para la instrucción de la nueva sociedad civil: los niños, los adolescentes, en cuanto a cómo debían de ser tratados, educados, formados. (Rengifo, Pinillo y Díaz, 2016a, p. 347).

El acto de teorización discursiva del educador es percibido por la emergencia de la singularidad narrativa escolar como palabrería obsoleta, que nada dice de la realidad que este percibe. El educador le aparece como un no-líder, un no-jefe, un no-guía. Una realidad en su comicidad teatral: realidad superflua depositaria de pura palabrería gris, sin sentido ni finalidad. La discursividad del educador emerge, como en una tira cómica, como una caricatura que mueve los labios ridículamente con la necesidad de decir algo. Sus gestos, acciones y posturas configuran una realidad cómica para el educando. Decir algo con sentido es la necesidad del educador: una buena broma para el educando. El educando es puro hedonismo. En la era digital, la realidad educando es un mar de opiniones, información, desinformación y banalidad. Su pensamiento se ha perdido en un mar de información y en un haz relacional de imágenes (McLaren, 1991). La imagen grotesca, cómica, trágica, dramática, en un primer plano enunciativo, que anuncia un trozo del plexo de vida de un sujeto vuelto personaje, tema, argumento. Acto que condiciona el imaginario colectivo de las hordas educables de hoy. La imagen se ha vuelto imperativo social. Significante cuya significación recae en el simplismo mediático de producir un estímulo comercial: producir un sentimiento en alguien sobre algo. La imagen se ha vuelto paradigma relacional societal. Engranaje motivacional en los procesos de interacción comunicativos tribales, no racionales, de las singularidades educables. Los jóvenes de hoy no desean ver clases, la imagen por WhatsApp crea un universo relacional de sentido, banal, pero al fin y al cabo de sentido, para quienes se comunican a espaldas del educador.

La singularidad educable ha reemplazado en su relación, en el acto de enseñanza-aprendizaje, el papel activo del educador por el del papel, más activo, de hecho, interactivo, del dispositivo móvil. El no-espacio, el dispositivo móvil reemplaza tanto a la singularidad educada como al espacio escolar, como a la totalidad del acto pedagógico. El no-espacio digital trivializa lo oficial e instituye, desde otro ángulo, lo comercial. Lo comercial, no-espacios tecnológicos como agentes que se funden con el ser biológico. Hoy acudimos a una sociedad realmente cíborg-zombi: niños, hombres y mujeres, fundidos en una relación orgánica con lo otro muerto, los no-espacios, los dispositivos móviles, actuando como sujetos regulados, producidos y reproducidos por una máquina digital: su propio celular. El no-espacio es objeto que regula, determina y construye. Regula la vida social, determina la vida privada y construye la vida ciberespacial. La sociedad de hoy es una sociedad de (...), con (...), dependiente del celular. Un pequeño aparato que condiciona todo un mundo, un sentir, un vivir. Prefigura una realidad. Tematiza un estilo de vida. Crea planos de interacción enunciativa y desinstituye otros planos ya no enunciativos. La memoria del dispositivo móvil, el tipo de cámara, su conectividad, su fisonomía, se presentan como un nuevo acontecimiento. Un acontecimiento en el cual un objeto se encarnó en la realidad del sujeto vivo vuelto pedagogo social. Dispositivo que por su funcionalidad se ha vuelto, para el educando, el no-espacio que desinstituye el espacio oficial e instituye el espacio móvil, fluido. Dispositivo que educa sin educar. Dispositivo que permite aprender sin procesos de aprensión real. Dispositivo que niega lo humano paradójicamente fundiéndose en lo humano. Dispositivo que regula, dirige y enseña. Metaobjeto que funde la vida en un proceso lineal de consumo informativo. Consumo informativo que niega la realidad educador. Negación que es instituida por las lógicas de las acciones juveniles. Juventud, consumo, 
información, aprendizaje son la cadena social laboral del nuevo orden mundial, y con ello, del proceso educativo. Las horas de jóvenes imponen lo que se ha de aprender, para ser un actor socialmente deseable, modos, formas, procedimientos de interacción, son estos quienes dicen el mundo de hoy. La vejez es signo de inutilidad y decadencia. La juvenilización del mundo social, laboral, cultural es moneda corriente. Se necesita mano de obra calificada a una edad más temprana. Se requiere explotar a un ejército de obreros en el acontecer de su vida productiva. De ahí que los nuevos íconos sociales sean siempre jóvenes empresarios, deportistas o de cualquier otro orden, que hayan triunfado (McLaren, 1991). Esto es, que hayan hecho fortuna. Que hayna conquistado el mundo. Que tengan millones de dólares en su cuenta bancaria.

El complejo de Alejandro Magno ha vuelto a emerger: necesidad de conquistar el mundo a una edad temprana. Los jóvenes caen víctimas, graciosamente, del sistema. Son los más ingenuos en un mundo que ha sido codificado, diseñado e instituido para ellos. El sistema los ha pensado como los mejores clientes de un mundo sin fronteras, los desencarna de su naturaleza creadora y los encarna en una realidad artificial. Por ello su importancia: el consumo es su a priori. Su ingenuidad es directamente proporcional a su arrogancia, estupidez y vanidad. Son el instrumento del sistema para un mundo que ha acabado con toda diferencia, bajo la enunciación perlocucionaria cliente. Los jóvenes educandos han terminado siendo los títeres de un mundo deshumanizado, desencarnado. El movimiento pendular con que se les duerme: lo otro, el otro pedagogo, la red, el ciberespacio, los dispositivos móviles. Estar dormidos es su costumbre. El sistema funciona bien. Nuevos paquetes interactivos en sus no-espacios móviles los hacen dormir mejor. El sistema sigue asegurando autistas, zombis, cíbors, con ello, ganancias. El sedentarismonómada (Rengifo, Pinillo y Díaz, 2016b) ha sido todo un éxito. Más aún, su perpetuación apenas empieza. Estar en el estado de viajar desde un mismo punto, sin la necesidad física de la traslación del cuerpo en el espacio, es un placer social. El nomadismo es principio de legitimación del sedentarismo. Velocidad, desplazamiento ciberespacial, fluidez son todos sinónimos de esta realidad, la nómada, para perpetuar la postura fisiológica sedentaria. De ahí, la importancia de desplazar al maestro e instituir al otro pedagogo. El aprendizaje ha de estar garantizado, la horda de jóvenes lo asegura. Su necesidad de consumo la justifica. $\mathrm{Su}$ ansia de información lo requiere. El aprendizaje superfluo, ligero, veloz es menester.

\section{Espiral de fuga: un entretejerse en un proceso de formación co-constructivo}

¿Cómo enfrentar esta situación tan lamentable? ¿Cómo hacer para reivindicar el papel trasformador del maestro? Proponemos que la salida plausible a la problemática pedagógica y sociocultural que atraviesa la escuela en el ámbito de la enseñanza en era digital, en la cual están inmersos la singularidad del educador y el educando, como actores sociales dispersos de la unidad relacional de antaño, se encuentra en la reconstrucción de la praxis formativa en una espiral de fuga. Denominamos praxis formativa a la restauración de un proceso educativo en el que se reinstituyan cinco componentes básicos: (1) el maestro como actor fundante del acto educativo (Zuluaga, 1996) en cuanto singularidad que es capaz de hacer emerger algo nuevo, una inquietud, una risa, un llanto, un sentimiento, un amor, un desamor, una emoción, algo; (2) la singularidad educable como agente activo, dinámico, vivo, orgánico, con el que se debe entretejer, a través del diálogo (Freire, 1971), la narración (Giroux, 2004) los gestos, las posturas, un flujo relacional de sentido; (3) un currículo que rescate el valor formativo de temas fundantes de la vida humana como serían una pedagogía del cuerpo, una pedagogía de la alimentación, una pedagogía de la sexualidad, una pedagogía del espíritu (Rengifo, 2016); (4) Un espacio que pueda ser considerado, pensado, proyectado como una arquitectura dinámica, móvil, interactiva, cómoda, circular, en la que las cuatro paredes puedan ser superadas y le den paso a otra cosa, un no-espacio, un espacio sin espacio; y (5) un flujo relacional constante con lo que funde la vida del educando: su familia, su tribu, su grupo, una relación constante entre escuela-entorno afectivo de educando (McLaren, 1991). Desde luego esto requiere de unas políticas públicas en las que se pueda pensar de otro modo. Es un esfuerzo que exige trabajo y disciplina. Es dejar de aparentar ser para llegar a ser. Esto implica un proceso de liberación y co-construcción de dos singularidades que deben emerger inquietas. El educador debe dejar de ser un profesional al servicio de intereses mercantiles, para transformarse en un liberador de almas jóvenes y creador de nuevos nexos de sentido. La singularidad educable debe dejar de ser una simple singularidad narrativa, para transmutar en co-constructor de un proceso interrelacional, bajo el pretexto de una conversación entablada sobre algo realmente relevante, un problema.

Pensar la educación actual de acuerdo a problemas reales, en términos teóricos o prácticos, es darse 
la oportunidad de permitir que surja una relación pedagógica en torno a algo. La singularidad educable no ha de resolver el problema, no se debe pensar que el problema es una situación pensada de antemano y ya resuelta; antes bien, este es la posibilidad de que lo realmente importante del acto educativo emerja: pensar. Pensar no puede seguir siendo considerado un ejercicio de indagación propio de las mentes brillantes de los investigadores. Debe ser, antes que nada, una situación constante de la clase.

Tal propuesta teórica consiste en que, tanto la singularidad educador como la singularidad educando sean capaces de convertirse en educadores transformadores $^{8}$, agentes societales críticos y creativos de la realidad, dejando el discurso de la desesperanza a un lado, y dando paso a un lenguaje de la esperanza (McLaren,1991), a una noción de educador-liberador, y a la recuperación de una espiritualidad-narrativaemancipadora. Por tal razón, el aula de clases debe transmutar en un espacio de reflexión discursiva y en una praxis revolucionaria, en donde no solo los deseos y anhelos de estos sean válidos, sino los de todos aquellos que los circundan. La reconstrucción de la praxis formativa consiste en adentrarse en una amalgama de posibilidades discursivas distintas, únicas, diferentes y auténticas, por parte subjetividades lingüísticas que poseen las mismas oportunidades políticas, sociales y económicas, en cuanto seres críticos y reflexivos.

La reconstrucción de la praxis formativa consiste en dar paso a una mirada diferente al contexto sociocultural y político de las diversas subjetividades discursivas desde lo que son, y no desde lo que los medios masivos de comunicación, la escuela o las instituciones de poder quieren que sean (Foucault, 1979). Es quitar de los ojos la venda de la inmediatez tecnológica y liberarnos de la cadena posmoderna del individualismo hedonista, del vacío existencial y de la paradoja de la masividad política, cultural e ideológica de la pedagogía del consumo, de la cultura pornográfica audiovisual y del sedentarismo-nómada, a la cual nos encontramos anclados. Este, desde luego, no es un mensaje subliminal para apartarse de la norma y desestabilizar lo institucionalmente establecido. Es, por el contrario, la invitación a realizar una exégesis deconstructiva del sistema en el cual nos encontramos, bien en el rol de estudiantes, o bien en el de

8 Por educadores transformadores de la realidad entendemos la capacidad que tanto el educador como el educando deben adquirir, para poder evidenciar las paradojas del mundo capitalista dominante, y hacer del aula de clases un lugar de discusión y de acción participativa entre distintas subjetividades discursivas en la comprensión y producción de un mundo mejor. profesores, para problematizarlo, ponerlo en crisis, encontrar sus fisuras y evidenciar las paradojas que utiliza, que desangra lentamente el imaginario de los actores sociales convirtiéndose en amo y verdugo de cada uno, por cuanto no permite ni da cabida a la reflexión crítica. Es hacer un alto en el camino y ver la realidad no bajo el velo de mundo de la ilusión y la fantasía propuesta por el neoliberalismo del pluralismo pasivo, en donde todo es posible si se adentra en la lógica del sistema de la pedagogía del consumo, o por las doctrinas conservadoras que perpetúan la tradición educativa y sociopolítica opresiva a la cual se deben doblegar los actores sociales en todo momento; sino que es un avistamiento bajo el crisol de la autenticidad, de intelectualidades lingüísticas críticas capaces de realizar actos de inclusión, de empoderamiento propios y ajenos de sí, como de los demás, de modo tal que se dé paso a la concepción de una cultura civil y pedagógica pluralista en sentido crítico, donde la diferencia del otro no deviene tan distinta a la mía -como generalmente les han hecho creer a los individuos-, sino que por el contrario, el otro aparece como una singularidad auténtica semejante a la propia, por cuanto su modo de concebir al mundo no es tan diametralmente opuesto al modo en que uno concibe el propio.

En suma, esperamos que el profesional de hoy pueda llegar a transmutar en el real maestroeducador del que hablaba Nietzsche, y para ello proponemos que todo educador debe por obligación generar procesos de des-aprensión institucionales académicos, políticos y sociales, y que todo maestro está obligado a generar en sus estudiantes mecanismos auténticos de creación. El resultado: un hombre formado por y para una vida plena.

\section{Conclusión}

En conclusión, podemos decir que la imposibilidad de la enseñanza en la actualidad se debe al anclaje estructural que el sistema educativo realiza dentro de la gran hidra sistémica. Anclaje en el que la unidad de sentido del acto educativo de antaño ha desaparecido, por la implantación de venta de paquetes informativos. El sistema educativo vive feliz reproduciendo en su interior la tendencia cultural de la pedagogía del consumo, basada en una ética comerciante, que a su vez no expresa más que la tendencia a dirigir a la sociedad hacia un sedentarismo-nómada del cual el profesional no es otra cosa que una coextensión lastimera del mercado: ser obrero es un imperativo educativo, ser cliente es una necesidad existencial.

La singularidad educable con sus prácticas dinámicas propias del mundo tecno-científico 
coextensivas de una pedagogía del consumo, y la singularidad educada, con su discurso teórico informativo, soso, aburrido, son el mejor ejemplo de la teatralidad de un mundo sin sentido, absurdo y vacío, en el que la institución es el dramaturgo (el que dice cómo y por qué se hace la obra), el conocimiento es el juego entre saber, poder y lenguaje en una relación de poder entre el que dice que sabe y el que desea no saber; el salón de clase, el escenario de unas mímicas corporales, unas narrativas propias y unas acciones carentes de significado; el educador, el actor principal de una comedia sin comediante, y el educando, el gran público de una farsa ridícula, donde uno y otro están más por obligación que por convicción. La pereza de ambos se entreteje en un mar de palabras sin sentido ni problematización reales: acabar la clase rápido, desean unos y piensan otros. El momentum eterno de entretejerse es rebasado por el momentum eterno de lo superfluo. La experiencia de un acto superficial, vacío, carente de sentido es la constante pedagógica del mundo actual.

La salida a tal panorama la hallamos a través de lo que nosotros llamamos praxis formativa, que no es más que la autocomprensión del educador como un verdadero maestro, esto es: un liberador de las ataduras de este mundo vacío, alienante, mercantil, y un creador y generador de nuevos nexos de sentido, que parten del desarrollo del potencial de creatividad que posee el ser humano decidido, libre y dueño de sí. Para ello, se hace necesario el pensar acerca de los problemas. El considerar la otredad educable como agente social activo partícipe del acto educativo es menester. El entretejerse ha de ser principio rector.

\section{Referencias}

Bauman, Z. (2004). La modernidad líquida. Buenos Aires: Fondo de Cultura Económica.

Bolk, L. (2007). Teoría de la retardación. Cali: Universidad del Valle.

Chervel, A. (1991). Historia de las disciplinas escolares reflexiones sobre un campo de investigación. Revista de Educación, 295, 59-111.
Corea, C. y Lewkowicz, I. (1995). Pedagogía del aburrido. Buenos Aires: Paidós.

Deleuze, G. y Guatari, F. (1997). Mil Mesetas: Capitalismo y esquizofrenia. Valencia: Pre-textos.

Esquilo. (2000). Prometeo encadenado. Madrid: EDAF.

Foucault, M. (1968). Las papalbras y las cosas. Buenos Aires: Siglo XXI.

Foucault, M. (1979). Vigilar y castigar. Buenos Aires: Siglo XXI.

Freire, P. (1971). La pedagogía del oprimido. Barcelona: Siglo XXI.

Giroux, H. (2004). Teoría y resistencia en educación. Buenos Aires: Siglo XXI.

Habermas, J. (1999). Teoría de la acción comunicativa. Madrid: Tusquets.

Lipovetsky, G. (1986). La era del vacío. Barcelona: Anagrama.

McLaren, P. (1991). Pedagogía crítica, resistencia cultural y producción del deseo. Buenos Aires: Aique.

Nietzsche, F. (1997. Así habló Zaratustra. Barcelona: Gedisa.

Nietzsche, F. (2000a). Schopenhauer como educador. Barcelona: Tusquets.

Nietzsche, F. (2000b). Sobre el porvenir de nuestras instituciones educativas. Barcelona: Tusquets.

Platón. (1980). La República. Madrid: EDAF.

Rengifo, J. (2015). Amigo lector: Sobre la miseria humana. Revista Pensamiento y Acción, 20, 128-139.

Rengifo, J. (2016). Debilidades de la teoría política de Rawls e improcedencia del consenso entrecruzado en el liberalismo político. Escritos, 23(51).

Rengifo, J. y Pinillo, M. y Díaz, H. (2016a). La paradoja del espacio académico: disciplinar sin disciplina. Revista Colombiana de Educación, 70, 341-360.

Rengifo, J., Pinillo, M. y Díaz, H. (2016b). El sedentarismo nómada. Madrid: Revista Internacional de Humanidades, 5(1).

Zuluaga, O. (1996). Pedagogía e historia. Medellín: Universidad de Antioquia. 


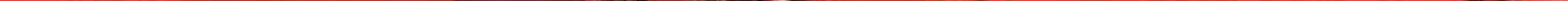

